\title{
Granulomatosis With Polyangiitis in Otolaryngologist Practice: A Review of Current Knowledge
}

\author{
Joanna Wojciechowska ${ }^{1}$ - Wojciech Krajewski $\cdot$ Piotr Krajewski $\cdot$ Tomasz Kręcicki ${ }^{1}$ \\ ${ }^{1}$ Department and Clinic of Otolaryngology-Head and Neck Surgery, ${ }^{2}$ Department of Urology, Wroctaw Medical University, Wroctaw, Poland
}

\begin{abstract}
Granulomatosis with polyangiitis (GPA) is an idiopathic vasculitis of medium and small arteries, characterized by necrotizing granulomatous inflammation. GPA typically affects upper and lower respiratory tract with coexisting glomerulonephritis. This disease is generally characterized by antineutrophil cytoplasm antibodies (ANCA), nevertheless, there are rare cases with negative ANCA. GPA affects people at any age, with predominance of the sixth and seventh decade of life. In $80 \%-95 \%$ of the patients the first symptoms of GPA are otorhinolaryngological manifestations of head and neck including nose/sinuses, ears, eyes, larynx/trachea, oral cavity, and salivary glands. Diagnosis of GPA is based on Criteria of the American College of Rheumatology. In clinical practice diagnosis, the presence of distinctive ANCA antibodies and biopsy of affected organ are crucial. GPA must be differentiated from neoplastic, infectious or inflammatory ulcerative lesions of the head and neck. The standard treatment procedure is divided into two essential phases, induction and maintenance. The induction phase is based on combination of systemic corticosteroid and immunosuppressant therapy, whereas the maintenance phase comprises corticosteroids and azathioprine/methotrexate supplementation. Surgical treatment ought to be considered for patients who are not responding to pharmacotherapy.
\end{abstract}

Keywords: Granulomatosis with Polyangiitis; Wegener Granulomatosis; Otolaryngology

\section{INTRODUCTION}

Granulomatosis with polyangiitis (GPA), previously known as Wegener granulomatosis, is an idiopathic vasculitis of medium and small arteries, characterized by necrotizing granulomatous inflammation of the respiratory tract with coexisting glomerulonephritis. The estimated incidence of GPA in Europe is 5-10 cases per 1 million populations [1].The GPA is a serious disease, mean survival time of untreated generalized GPA is 5 months due to renal or lung failure. Modern immunosuppressive treatments methods greatly improved patient outcomes and estimated median survival time to 21.7 years after diagnosis [2]. In the recent period of time, studies focusing on the suitability of biological agents in modifying the course of both systemic and localised disease have emerged. Spreading knowledge about this

- Received January 6, 2015

Revised February 16, 2015

Accepted February 23, 2015

- Corresponding author: Joanna Wojciechowska

Department and Clinic of Otolaryngology-Head and Neck Surgery,

Wrocław Medical University, Borowska 213, 50-556 Wrocław, Poland

Tel: +48-71-734-3700, Fax: +48-71-734-3700

E-mail: wojciechowska.joan@gmail.com modern therapy in GPA among otolaryngologists may contribute to the improvement of prognosis.

GPA is generally characterized by antineutrophil cytoplasm antibodies (ANCA), although in rare cases of limited GPA, ANCA may not be present. As is was proven in in vitro studies ANCA activate neutrophils, enhance their adherence to endothelium, causing their degranulation and harming endothelial cells [3]. The disease affects people at any age, but the most common age of presentation of GPA is the sixth and seventh decade of life. Most often symptoms of GPA belong to classic triad of upper respiratory tract, lungs and kidneys, although any organ may be affected. In $80 \%-95 \%$ of the patients the first symptoms of GPA are otorhinolaryngological manifestations of head and neck [4]. In some cases otorhinolaryngological symptoms are sole sign of the disease and those forms, so-called "limited GPA" in contrast to more advanced stages with systemic vasculitis called "generalized GPA". Limited GPA phenotype is often more recurrent and refractory and it is more likely to affect younger and more female population [5]. Generalized GPA typically includes renal and/or pulmonary involvement and systemic symptoms such as fever, asthenia, anorexia or weight loss are more probable [6]. Phenotypes of GPA differ from each oth-

Copyright (C) 2016 by Korean Society of Otorhinolaryngology-Head and Neck Surgery.

This is an open-access article distributed under the terms of the Creative Commons Attribution Non-Commercial License (http://creativecommons.org/licenses/by-nc/4.0)

which permits unrestricted non-commercial use, distribution, and reproduction in any medium, provided the original work is properly cited. 
er also in specific cytokine pattern. The limited form is characterized by Th1 lymphocyte polarization, as opposed to the generalized form with greater Th2 lymphocyte polarization [7]. During the course of GPA, the transformation from limited to generalized form and vice-versa is possible.

\section{DIAGNOSTICS}

According to Criteria of the American College of Rheumatology (ACR; 1990), GPA is diagnosed if 2 or more of the following 4 criteria are met: (1) sinus involvement; (2) lung X-ray showing nodules, a fixed pulmonary infiltrate or cavities; (3) urinary sediment with hematuria or red cell casts; and (4) histological granulomas within an artery or in the perivascular area of an artery or arteriole. The sensitivity and specificity of the ACR criteria are respectively $88.2 \%$ and $92.0 \%$ [8].

Currently in clinical practice diagnosis is usually based on presence of distinctive ANCA and biopsy of affected organ.

The main component of GPA diagnostics is serologic evaluation of cytoplasmic pattern of ANCA. ANCA, mainly of the IgG type, are targeted against proteinase 3 (cytoplasmic anti-neutrophil cytoplasmic antibody, c-ANCA) or myeloperoxidase (perinuclear- anti-neutrophil cytoplasmic antibody, p-ANCA). both main neutrophil granule components. To determine level of ANCA immunofluorescence and enzyme-linked immunosorbent assay are used.

c-ANCA are specific for GPA, while p-ANCA are associated with inflammatory bowel disease, rheumatoid arthritis, autoimmune liver disease etc.

During flares the sensitivity and specificity of testing for c-ANCA are $91 \%$ and $99 \%$, respectively [9]. In the generalized GPA, ANCA are elevated in $90 \%-95 \%$ of patients, whereas in the limited stage of GPA in the ear-nose-throat region, positive levels of c-ANCA may occur in only $46 \%-70 \%$ of patients $[5,10]$.

Biopsy is usually used when ANCA testing is nondiagnostic or uncertain. In positive biopsies granulomatous inflammation including palisading granulomas, scattered giant cells, vasculitis or necrotizing granulomata can be found [11]. In localized disease, the role of the biopsy increases, because localized GPA has lower decisive predictive value of c-ANCA. In those patients biopsy should be performed to avoid oversight of c-ANCA negative GPA (10). Because up to $50 \%$ of specimens may be nondiagnostic, in some patients repeat biopsies are necessary [3].

Some findings on computed tomography (CT) scans like bone destruction of the nasal cavity, maxillary sinuses and mastoid air cells, as well as sclerosing osteitis and bony thickening in the same locations can be useful in diagnose making [11]. GPA must be differentiated from neoplastic, infectious or inflammatory ulcerative lesions of the head and neck. GPA can be mistakenly taken for neoplasms as natural killer T-cell lymphoma or infections such as tuberculosis, aspergillosis and leishmaniasis, rarely occurring in our region leprosy, inflammatory conditions as sarcoidosis, and finally cocaine induced midline destructive lesions [12]. Other diagnoses that are also associated with the ANCA such as systemic lupus erythematosis (SLE), Churg-Strauss syndrome, microscopic polyangiitis and vasculitis induced by drug reactions, must be differentiated from GPA. To distinguish between those diseases some hints can be useful. SLE is associated with the presence of immune complex deposition and presence of anti-dsDNA or anti-Sm antibodies, which are not present in other potential diseases [13]. Drug reactions require history of various drugs use within 7 to 21 days of symptom onset. The biggest association was demonstrated for the propylthiouracil, but other drugs as methimazole, carbimazole, benzylthiouracil, hydralazine, anti-tumor necrosis factor- $\alpha$ (anti-TNF- $\alpha$ ), sulfasalazine, D-penicillamine, and minocycline were described to induce vasculitis symptoms [14]. Microscopic polyangiitis in contrast to other diseases do not contain granulomas and Churg-Strauss syndrome include presence of asthma and eosinophilia, symptoms lacking in GPA [15].

\section{TREATMENT}

Treatment of GPA must be patient-adjusted. Adequate dosage of drugs should be administered to prevent severe side effects on the one hand, insufficient treatment with a risk of failure or early relapse on the other. The standard procedure is divided into two essential phases, induction and maintenance. The main goal of the first phase is rapid remission induction, which should last up to 6 months depending on clinical condition. The purpose of the second phase, which lasts $12-24$ months, is to maintain remission and prevent aggravation of disease (Table 1) [16].

According to the current recommendations for generalized GPA the induction phase is based on combination of systemic corticosteroid and immunosuppressant therapy. Typical glucocorticoid therapy includes oral prednisone administration (starting dose of prednisone $-1 \mathrm{mg} / \mathrm{kg} /$ day with a maximum of 80 $\mathrm{mg}$ /day) with a dose reduction after 3-4 weeks. In severe cases oral therapy is preceded by intravenous bolus of methyloprednizolone (7.5-15 mg/kg/day) administered for 1-3 days [11,17].

Cyclophosphamide (CYC) (alkylating agent) is common in first-line treatment (standard dose of CYC is $2 \mathrm{mg} / \mathrm{kg} /$ day or $600 \mathrm{mg} / \mathrm{m}^{2}$ ). CYC is used every 2 weeks for 1 month (at a dose of $600 \mathrm{mg} / \mathrm{m}^{2}$ ) and subsequently in appropriately modified dosage until achieving remission. Due to potential toxicity of cumulative dose during long-term exposure, dosage of CYC should be as low as possible [11,17].

Rituximab (RTX) (anti-CD20 monoclonal antibody) therapy should be additionally offered to patients with a relapse after complete cycle of CYC or when CYC is contraindicated. RTX should be given once a week at a dose of $375 \mathrm{mg} / \mathrm{m}^{2}$ for a month. RTX allows lowering immunosuppressants exposure, 
Table 1. Drugs used in granulomatosis with polyangiitis therapy

\begin{tabular}{|c|c|c|c|}
\hline Drug & Phase of therapy & Drug action & Common adverse effects \\
\hline Glucocorticoids & $\begin{array}{l}\text { Induction and } \\
\text { maintenance }\end{array}$ & $\begin{array}{l}\text { Anti-inflammatory and } \\
\text { immunosuppressive agent }\end{array}$ & $\begin{array}{l}\text { Weight gain, hyperglycemia, mood swings, easy bruising, infection } \\
\text { risk, cataracts, hypertension, osteoporosis, Cushing syndrome }\end{array}$ \\
\hline Cyclophosphamide & Induction & Alkylating agent & $\begin{array}{l}\text { Cytopenias, nausea and vomiting, diarrhea, hair loss, teratogenesis } \\
\text { (avoid in pregnancy), hemorrhagic cystitis, long-term risk of } \\
\text { infertility, and malignancy }\end{array}$ \\
\hline Rituximab & $\begin{array}{l}\text { Induction and } \\
\text { maintenance }\end{array}$ & Anti-CD20 monoclonal antibody & $\begin{array}{l}\text { Infusion reactions neutropenia, hypogammaglobulinemia } \\
\text { Infections (including small risk of progressive multifocal } \\
\text { leukoencephalopathy) } \\
\text { Potential for viral reactivation (e.g., hepatitis B) } \\
\text { Development of other autoimmune conditions }\end{array}$ \\
\hline Plasmapheresis & Induction & $\begin{array}{l}\text { Extracorporeal separation } \\
\text { of blood components }\end{array}$ & $\begin{array}{l}\text { Increased risk of sepsis especially if combined with cyclophosphamide } \\
\text { Potential risk of transmission of viral infection if using infected blood } \\
\text { products }\end{array}$ \\
\hline $\begin{array}{l}\text { Intravenous } \\
\text { immunoglobulin }\end{array}$ & Induction & $\begin{array}{l}\text { Intravenous plasma protein (lgG) } \\
\text { replacement therapy }\end{array}$ & $\begin{array}{l}\text { Potential risk of transmission of viral infection if using infected blood } \\
\text { products } \\
\text { Allergic reaction in patients who are IgA deficient (due to expected } \\
\text { levels of small amounts of IgA in the preparation) } \\
\text { Headaches, flushing, fever, chills, fatigue, nausea, and diarrhea are } \\
\text { transient reactions during infusions }\end{array}$ \\
\hline Abatacept & Induction & Inhibitor of CTLA-4 signals to T cells & $\begin{array}{l}\text { Headache, hypertension, nausea, liver dysfunctions, infections of } \\
\text { upper respiratory tract }\end{array}$ \\
\hline Methotrexate & Maintenance & Antimetabolite and antifolate agent & Nausea, diarrhea, mouth ulcers, hair loss, cytopenia, liver dysfunction \\
\hline Azathioprine & Maintenance & Purine analogue & $\begin{array}{l}\text { Nausea, diarrhea, mouth ulcers, hair loss, cytopenia, liver } \\
\text { dysfunction, nonmelanoma skin tumors (advise sun protection) }\end{array}$ \\
\hline Belimumab & $\begin{array}{l}\text { Induction and } \\
\text { maintenance }\end{array}$ & Anti-B-cell activating factor antibody & Bacterial infections, nausea, leucopenia, depression, insomnia \\
\hline
\end{tabular}

through reduction of CYC and glucocorticoid dose with few major adverse effects [18-20]. RTX should be preferred over CYC in premenopausal women whenever possible, because of the potential induction of infertility of CYC [21].

As it was proven single course of RTX was as effective as continuous conventional immunosuppressive therapy for the induction and maintenance of remissions over the course of 18 months [22]. In recently published trials comparing CYC and RTX in remission induction authors demonstrated that RTX has an efficacy in remission induction comparable to that of CYC and is likely superior in relapsing patients [19,22-24].

In severe cases of GPA with pulmonary hemorrhage, plasmaexchange therapy combined with corticosteroid and immunosuppressant should be considered [25].

Other agents that have demonstrated effectiveness in smallscale studies are purine and pyrimidine antimetabolites, mycophenolate mofetil (antiproliferative agent), leflunomide (antiproliferative agent), antithymocyte globulin (T-cell depletion antibody), and 15-deoxyspergualin (inhibitor of interleukin-2-stimulated maturation of T cells) [26].

Anti-TNF- $\alpha$ biological drugs have shown variable effectiveness in treatment of GPA, with positive effects of infliximab but no significant positive findings with etanercept (TNF inhibitor) $[26,27]$. Thus, etanercept should not be used as adjunct therapy.

Some reports suggest that intravenous immunoglobulin (IV Ig) can be considered when corticosteroids and CYC fail [28], however it was demonstrated that IV Ig, in comparison with the combination of steroids and immunosuppressants do not provide any therapeutic advantage in patients with GPA. Another drawback of IV Ig is its high price (one dose at $2 \mathrm{~g} / \mathrm{kg}$ for a 70 $\mathrm{kg}$ patient $=\$ 8,400$ ) [29].

Abatacept (inhibitor of CTLA-4 signals to T-cells) is proven to be associated with a high percentage of disease remission and prednisone discontinuation in GPA patients [30].

Severe GPA relapse should be treated just like initial GPA and other relapses should mean to restart maintenance therapy.

The maintenance phase, which is introduced after remission achievement, lasts up to 24 months and is based on oral corticosteroids and azathioprine/methotrexate supplementation. Discontinuation or use of low doses of maintenance therapy is associated with a higher relapse rate [31].

It was shown in some studies that methotrexate is safer than azathioprine, however both substances seem to be equivalent for maintenance therapy in patients with GPA after achieving remission [32].

In recently published MAINRITSAN trial it has been proven that RTX can be used as maintenance therapy as an alternative to azathioprine [33]. The results of more trials, especially on-going RITAZAREM and MAINRITSAN-2 are now keenly awaited to confirm those findings. Yet, current data support the use of RTX to maintain remission in patients at high risk of relapse or in patients who have experienced multiple relapses, or relapses 
while on alternative maintenance regimens. The optimal RTX dosing schedule, however, remains to be determined [34]. Results of RTX use in otolaryngology are generally good, however, there are available studies showing GPA otolaryngological manifestations endurance after RTX therapy $[18,35]$.

The success of B-cell-depleting therapy with RTX in both induction phase and maintenance phase of ANCA associated vasculitis has encouraged testing other B-cell-targeted therapies. Belimumab, anti B-cell activating factor antibody, has recently been approved by U.S. Food and Drug Administration for the treatment of SLE and is currently undergoing phase II/III clinical trials in vasculitides [36].

In order to avoid Pneumocystis jiroverci infection, trimetoprim/ sulfamethoxazole should be given during whole immunosuppressive therapy [17].

Surgical treatment ought to be considered for patients who are not responding to pharmacotherapy. There is a wide variety of procedures that patients may undergo including subglottic stenosis dilation, endoscopic sinus surgery, mastoidectomy, dacrocystorhinostomy, myringotomy or rhinoplasty [11].

\section{Nose and sinuses}

Sinonasal involvement is the most common manifestation of GPA in the head and neck region, it occurs in up to $85 \%$ of patients, and over $25 \%$ of patients have only sinonasal symptoms $[4,10]$. Tissue damage and bone destruction is caused by reduced blood flow due to vasculitis. Sinusal involvement usually starts in the septum area supplied by Kiesselbach plexus and then spreads to the paranasal sinuses [37]. Clinical symptoms can vary from inconsiderable nasal obstruction up to severe damage of the structures of outer nose, paranasal sinuses and skull base. However, the most frequent symptoms are nasal obstruction and discharge. Reduction in the sense of smell or cacosmia may appear as a result of purulent secretions associated with growth of bacterias such as Pseudomonas aeruginosa or Staphylococcus aureus [12]. Epiphora, other initial sign is caused by involvement of the nasolacrimal duct [38]. Participation of the nasal septum can cause perforations with whistling symptoms and in the more advanced cases "saddle nose" deformity [39].

Perforations of nasal septum and their expansion can cause collapse of the cartilaginous midvault of the nose. Cartilages of the nose change shape and orientation, which results in depressed appearance of the nose, so-called saddle-nose deformity. It deteriorates nasal obstruction and can cause anosmia.

Although that anterior septum supplied by Kiesselbach plexus is the most frequent region of sinonasal GPA, any structure in the sinonasal cavity, including mucosa, turbinates, septum, and sinuses may be affected. For that reason there is an indication to link both flexible endoscopy and CT scans in order to disclose all potential lesions.

Treatment of sinonasal GPA is difficult. Standard pharmacology or surgical interventions are often ineffective. To decrease the incidence of sinonasal intensifications culture-directed antibiotics followed by topical antibiotic irrigations can be helpful. Saline high-flow irrigations are also useful as an additional therapy to facilitate mucociliary clearance in affected nasal cavities.

Perforations of nasal septum are generally not treated [40]. Surgical management is not recommended due to poor tissue perfusion, bad wound healing and possible infections. It is vital in planning surgical treatment to identify an adequate period, when GPA is in remission. It is also important to choose suitable method of treatment that will have a chance of success in very poor vascular framework. Anyhow, saddle nose deformity can be successfully operated in the remission phase.

\section{Eye}

In some patients a granulomatous retro-orbital tumour can be formed as primary granulation tissue in retro-orbital area or as propagation of sinus lesions. In $2 \%$ of patients, GPA can appear as secondary proptosis [41]. Ocular symptoms such as necrotizing nodular episcleritis, scleritis, corneal ulcerations, and retinal vasculitis are also possible [42].

\section{Ear}

Otological manifestations can be found in $19 \%-61 \%$ of patients with GPA [43]. Ear involvement may be the initial and only symptom of GPA including external, middle and/or inner ear. Implication of a middle ear is the most common form of otological manifestation of GPA and it usually appears as unilateral or bilateral chronic otitis media with serous effusion and conductive hearing loss. Typically, otitis media in GPA is secondary to Eustachian tube dysfunction caused by nasopharyngeal involvement [39]. Chronic mastoiditis can also occur in patients with GPA. Facial nerve palsy with facial paralysis secondary to bone destruction is possible, but rare [44,45].

External ear manifestations are seldom observed. Its involvement can be described as erythematous or ulcerated lesions that mimic perichondritis [12].

Inner ear involvement can cause sensorineuronal hearing loss in $5 \%-31 \%$ of patients with GPA. The possible causes of hearing dysfunction include immunology complexes situated in cochlea, vasculitis of the cochlea vessels or compression of the vestibulocochlear nerve. Vartigo are quite rare, but possible concomitant symptom [39]. Hearing loss and vertigo may imitate Cogan syndrome (nonsyphilitic interstitial keratitis and bilateral audiovestibular deficits), leading to improper diagnosis [43].

Middle ear effusions, resistant to systemic therapy, can be managed with placement of a ventilation tube. Hearing amplification devices may be considered in patients with hearing loss.

\section{Salivary glands}

Another rare manifestation of GPA can be involvement of the large salivary glands. Parotid or submandibular glands may be swollen and sore, symptoms may mimic malignancy [46]. 


\section{Larynx and trachea}

Laryngeal and/or tracheal manifestations, such as ulcers or subglottic stenosis are infrequent, but in some cases can be sole demonstration of GPA [47]. Subglottic stenosis may relate to $10 \%-20 \%$ of patients with GPA and is more likely to occur in childhood $[11,43]$. The main reason of subglottic stenosis is destruction of surrounding tissues due to vasculitis and reduced blood flow followed by their excessive reconstruction. Narrowing up to $75 \%$ of subglottic diameter usually remains asymptomatic, whereas stricture of at least $80 \%$ of laryngx lumen can be life threatening. Patients usually present dyspnea, wheezing or stridor. Cough and hoarseness are observed rarely. Patients with symptoms suggesting presence of subglottic stenosis should be examined with flexible endoscopy and CT imaging. These methods can reveal circumferential subglottic narrowing $[12,43]$. Choice of treatment method depends on patient's clinical condition. In less advanced cases pharmacological treatment supported by topic inhaled glucocorticoids or optionally laser therapy can be sufficient. Despite pharmacotherapy up to $80 \%$ of patients have to undergo surgical interventions including translesional injection of corticosteroids, endoscopic dilation, radial laser incisions, stent placement, tracheostomy or resection of involved segment followed by reconstruction of missing section $[12,43,48]$. Any surgical procedure can lead to an aggravation of stenosis and for this reason it is recommended to initiate therapy with less invasive methods. However acute sublottic stenosis is life-threatening condition and often requires tracheotomy [49].

Supraglottic stenosis is a rare complication. So far, only one case has been reported in the literature [48].

\section{Oral cavity}

About 5\%-10\% patients with GPA experience at least one episode of pathological lesions in oral cavity in the course of the illness. Ulcerous changes may be localized on cheeks, tongue and palate. Another oral cavity manifestation is reddish colored irritating exophytic gingival swelling with petechial hemorrhages recalling strawberries [50]. In some cases it can be first symptom of GPA [51].

\section{CONCLUSION}

Otorhinolaryngologist is the first physician to contact for the majority of patients with GPA. This diagnosis must always be taken into consideration in patients with recurrent upper respiratory tract infections, otitis, mucosal ulcers and laryngitis. Proper and early diagnosis is crucial for imminent therapy implementation and allows avoiding irreversible organ damage. Studies, which appeared recently, create prospect for the introduction of less toxic and more effective treatment of GPA with biological agents.

\section{CONFLICT OF INTEREST}

No potential conflict of interest relevant to this article was reported.

\section{REFERENCES}

1. Watts RA, Lane SE, Scott DG, Koldingsnes W, Nossent H, GonzalezGay MA, et al. Epidemiology of vasculitis in Europe. Ann Rheum Dis. 2001 Dec;60(12):1156-7.

2. Reinhold-Keller E, Beuge N, Latza U, de Groot K, Rudert H, Nolle B, et al. An interdisciplinary approach to the care of patients with Wegener's granulomatosis: long-term outcome in 155 patients. Arthritis Rheum. 2000 May;43(5):1021-32.

3. Seo P, Stone JH.The antineutrophil cytoplasmic antibody-associated vasculitides. Am J Med. 2004 Jul;117(1):39-50.

4. Srouji IA, Andrews P, Edwards C, Lund VJ. Patterns of presentation and diagnosis of patients with Wegener's granulomatosis: ENT aspects. J Laryngol Otol. 2007 Jul;121(7):653-8.

5. Holle JU, Gross WL, Holl-Ulrich K, Ambrosch P, Noelle B, Both M, et al. Prospective long-term follow-up of patients with localised Wegener's granulomatosis: does it occur as persistent disease stage? Ann Rheum Dis. 2010 Nov;69(11):1934-9.

6. Stone JH; Wegener's Granulomatosis Etanercept Trial Research Group. Limited versus severe Wegener's granulomatosis: baseline data on patients in the Wegener's granulomatosis etanercept trial. Arthritis Rheum. 2003 Aug;48(8):2299-309.

7. Csernok E, Trabandt A, Muller A, Wang GC, Moosig F, Paulsen J, et al. Cytokine profiles in Wegener's granulomatosis: predominance of type 1 (Th1) in the granulomatous inflammation. Arthritis Rheum. 1999 Apr;42(4):742-50.

8. Leavitt RY, Fauci AS, Bloch DA, Michel BA, Hunder GG, ArendWP, et al. The American College of Rheumatology 1990 criteria for the classification of Wegener's granulomatosis. Arthritis Rheum. 1990 Aug;33(8):1101-7.

9. Rao JK, Weinberger M, Oddone EZ, Allen NB, Landsman P, Feussner JR. The role of antineutrophil cytoplasmic antibody (c-ANCA) testing in the diagnosis of Wegener granulomatosis. A literature review and meta-analysis. Ann Intern Med. 1995 Dec;123(12):925-32.

10. Borner U, Landis BN, Banz Y, Villiger P, Ballinari P, Caversaccio M, et al. Diagnostic value of biopsies in identifying cytoplasmic antineutrophil cytoplasmic antibody-negative localized Wegener's granulomatosis presenting primarily with sinonasal disease. Am J Rhinol Allergy. 2012 Nov-Dec;26(6):475-80.

11. Erickson VR, Hwang PH. Wegener's granulomatosis: current trends in diagnosis and management. Curr Opin Otolaryngol Head Neck Surg. 2007 Jun;15(3):170-6.

12. Trimarchi M, Sinico RA, Teggi R, Bussi M, Specks U, Meroni PL. Otorhinolaryngological manifestations in granulomatosis with polyangiitis (Wegener's). Autoimmun Rev. 2013 Feb;12(4):501-5.

13. Falk RJ, Jennette JC. Wegener's granulomatosis, systemic vasculitis, and antineutrophil cytoplasmic autoantibodies. Annu Rev Med. 1991 Feb;42:459-69.

14. Radic M, Martinovic Kaliterna D, Radic J. Drug-induced vasculitis: a clinical and pathological review. Neth J Med. 2012 Jan;70(1):12-7.

15. Mansi IA, Opran A, Rosner F. ANCA-associated small-vessel vasculitis. Am Fam Physician. 2002 Apr;65(8):1615-20.

16. Holle JU, Gross WL. Treatment of ANCA-associated vasculitides (AAV). Autoimmun Rev. 2013 Feb;12(4):483-6.

17. Comarmond C, Cacoub P. Granulomatosis with polyangiitis (Wegener): clinical aspects and treatment. Autoimmun Rev. 2014 Nov; 
13(11):1121-5

18. Martinez Del Pero M, Chaudhry A, Jones RB, Sivasothy P, Jani P, Jayne D. B-cell depletion with rituximab for refractory head and neck Wegener's granulomatosis: a cohort study. Clin Otolaryngol. 2009 Aug;34(4):328-35.

19. Stone JH, Merkel PA, Spiera R, Seo P, Langford CA, Hoffman GS, et al. Rituximab versus cyclophosphamide for ANCA-associated vasculitis. N Engl J Med. 2010 Jul;363(3):221-32.

20. Langford CA. Cyclophosphamide as induction therapy for Wegener's granulomatosis and microscopic polyangiitis. Clin Exp Immunol. 2011 May;164 Suppl 1:31-4.

21. Harward LE, Mitchell K, Pieper C, Copland S, Criscione-Schreiber LG, Clowse ME. The impact of cyclophosphamide on menstruation and pregnancy in women with rheumatologic disease. Lupus. 2013 Jan;22(1):81-6.

22. Specks U, Merkel PA, Seo P, Spiera R, Langford CA, Hoffman GS, et al. Efficacy of remission-induction regimens for ANCA-associated vasculitis. N Engl J Med. 2013 Aug;369(5):417-27.

23. Miloslavsky EM, Specks U, Merkel PA, Seo P, Spiera R, Langford $\mathrm{CA}$, et al. Rituximab for the treatment of relapses in antineutrophil cytoplasmic antibody-associated vasculitis. Arthritis Rheumatol. 2014 Nov;66(11):3151-9.

24. Jones RB, Tervaert JW, Hauser T, Luqmani R, Morgan MD, Peh CA, et al. Rituximab versus cyclophosphamide in ANCA-associated renal vasculitis. N Engl J Med. 2010 Jul;363(3):211-20.

25. Jayne DR, Gaskin G, Rasmussen N,Abramowicz D, Ferrario F, Guillevin L, et al. Randomized trial of plasma exchange or high-dosage methylprednisolone as adjunctive therapy for severe renal vasculitis. J Am Soc Nephrol. 2007 Jul;18(7):2180-8.

26. Lee RW, D'Cruz DP. Novel therapies for anti-neutrophil cytoplasmic antibody-associated vasculitis. Drugs. 2008;68(6):747-70.

27. Wegener's Granulomatosis Etanercept Trial (WGET) Research Group. Etanercept plus standard therapy for Wegener's granulomatosis. N Engl J Med. 2005 Jan;352(4):351-61.

28. Wiwatwongwana D, Esdaile JM, White VA, Dolman PJ. Intravenous immunoglobulin (IVIG) for orbital Wegener's granulomatosis. Can J Ophthalmol. 2012 Feb;47(1):82-3.

29. Fortin PM, Tejani AM, Bassett K, Musini VM. Intravenous immunoglobulin as adjuvant therapy forWegener's granulomatosis. Cochrane Database Syst Rev. 2013 Jan;1:CD007057.

30. Langford CA, Monach PA, Specks U, Seo P, Cuthbertson D, McAlear CA, et al. An open-label trial of abatacept (CTLA4-IG) in non-severe relapsing granulomatosis with polyangiitis (Wegener's). Ann Rheum Dis. 2014 Jul;73(7):1376-9.

31. Springer J, Nutter B, Langford CA, Hoffman GS, Villa-Forte A. Granulomatosis with polyangiitis (Wegener's): impact of maintenance therapy duration. Medicine (Baltimore). 2014 Mar;93(2):82-90.

32. Pagnoux C, Mahr A, Hamidou MA, Boffa JJ, Ruivard M, Ducroix JP, et al. Azathioprine or methotrexate maintenance for ANCA-associated vasculitis. N Engl J Med. 2008 Dec;359(26):2790-803.

33. Guillevin L, Pagnoux C, Karras A, Khouatra C,Aumaitre O, Cohen P, et al. Rituximab versus azathioprine for maintenance in ANCA-associated vasculitis. N Engl J Med. 2014 Nov;371(19):1771-80.

34. Daikeler T, Kistler AD, Martin PY, Vogt B, Huynh-Do U. The role of rituximab in the treatment of ANCA-associated vasculitides (AAV). Swiss MedWkly. 2015 Feb;145:w14103.

35. Malm IJ, Mener DJ, Kim J, Seo P, Kim YJ. Otolaryngological progression of granulomatosis with polyangiitis after systemic treatment with rituximab. Otolaryngol Head Neck Surg. 2014 Jan;150(1):68-72.

36. Lenert A, Lenert P. Current and emerging treatment options for ANCA-associated vasculitis: potential role of belimumab and other BAFF/APRIL targeting agents. Drug Des Devel Ther. 2015 Jan;9: 333-47.

37. Lloyd G, Lund VJ, Beale T, Howard D. Rhinologic changes in Wegener's granulomatosis. J Laryngol Otol. 2002 Jul;116(7):565-9.

38. Wong RJ, Gliklich RE, Rubin PA, Goodman M. Bilateral nasolacrimal duct obstruction managed with endoscopic techniques. Arch Otolaryngol Head Neck Surg. 1998 Jun;124(6):703-6.

39. Gottschlich S, Ambrosch P, Kramkowski D, Laudien M, Buchelt T, Gross WL, et al. Head and neck manifestations of Wegener's granulomatosis. Rhinology. 2006 Dec;44(4):227-33.

40. Rasmussen N. Management of the ear, nose, and throat manifestations of Wegener granulomatosis: an otorhinolaryngologist's perspective. Curr Opin Rheumatol. 2001 Jan;13(1):3-11.

41. Morales-Angulo C, Garcia-Zornoza R, Obeso-Aguera S, Calvo-Alen J, Gonzalez-Gay MA. Ear, nose and throat manifestations of Wegener's granulomatosis (granulomatosis with polyangiitis). Acta Otorrinolaringol Esp. 2012 May-Jun;63(3):206-11.

42. Choudhary MM, Hajj-Ali RA, Lowder CY. Gender and ocular manifestations of connective tissue diseases and systemic vasculitides. J Ophthalmol. 2014;2014:403042.

43. Alam DS, Seth R, Sindwani R, Woodson EA, Rajasekaran K. Upper airway manifestations of granulomatosis with polyangiitis. Cleve Clin J Med. 2012 Nov;79 Suppl 3:S16-21.

44. McCaffrey TV, McDonald TJ, Facer GW, DeRemee RA. Otologic manifestations of Wegener's granulomatosis. Otolaryngol Head Neck Surg (1979). 1980 Sep-Oct;88(5):586-93.

45. Takagi D, Nakamaru Y, Maguchi S, Furuta Y, Fukuda S. Otologic manifestations of Wegener's granulomatosis. Laryngoscope. 2002 Sep;112(9):1684-90.

46. Specks U, Colby TV, Olsen KD, DeRemee RA. Salivary gland involvement in Wegener's granulomatosis. Arch Otolaryngol Head Neck Surg. 1991 Feb;117(2):218-23.

47. Daum TE, Specks U, Colby TV, Edell ES, Brutinel MW, Prakash UB, et al. Tracheobronchial involvement in Wegener's granulomatosis. Am J Respir Crit Care Med. 1995 Feb;151(2 Pt 1):522-6.

48. Belloso A, Estrach C, Keith AO. Supraglottic stenosis in localized Wegener granulomatosis. Ear Nose Throat J. 2008 Jul;87(7):E11-4.

49. Polychronopoulos VS, Prakash UB, Golbin JM, Edell ES, Specks U. Airway involvement in Wegener's granulomatosis. Rheum Dis Clin North Am. 2007 Nov;33(4):755-75.

50. Knight JM, Hayduk MJ, Summerlin DJ, Mirowski GW. "Strawberry" gingival hyperplasia: a pathognomonic mucocutaneous finding in Wegener granulomatosis. Arch Dermatol. 2000 Feb;136(2):171-3.

51. Wawrzycka K, Szczeklik K, Darczuk D, Lipska W, Szczeklik W, Musiał J. Strawberry gingivitis as the first manifestation of granulomatosis with polyangiitis. Pol Arch MedWewn. 2014;124(10):551-2. 